\title{
Analysis of frozen section compared to permanent section: a 2 years study in a single tertiary care hospital
}

\author{
Sudha Ayyagari ${ }^{1}$, Anusha Potnuru ${ }^{1}$, Sk Aamer Saleem $^{1}$, Pavani Marapaka $^{1}$ \\ ${ }^{1}$ Kamineni academy of medical sciences and research centre, Hyderabad, India
}

\author{
Keywords: \\ Accuracy; \\ Comparison; \\ Frozen section; \\ Permanent section;
}

\begin{abstract}
Background: Frozen section is a commonly used tool for intraoperative consultation giving valuable information for patient management. Analysis of diagnosis during frozen section and subsequent permanent section allows the pathologist to review the diagnostic accuracy.
\end{abstract}

Materials and methods: In this 2-year retrospective study, 66 tissues received for intraoperative consultation were studied with the corresponding permanent sections on analysis. The diagnosis was either concordant or discordant. The diagnostic accuracy, sensitivity, and specificity were calculated.

Results: 65 of 66 cases had a concordant diagnosis on frozen sections and permanent sections. The diagnosis was discordant in one case due to the masking of a tumor by heavy inflammation. The diagnostic accuracy, sensitivity, and specificity were $98.48 \%, 96.8 \%$, and $100 \%$ respectively.

Conclusions: The results of our study compared well with those of other institutions, thereby emphasizing the value of frozen sections as a valuable test for intraoperative surgical consultation.

\section{Correspondence:}

Dr. Anusha Potnuru, MD

Department of Pathology

Kamineni Academy of Medical Sciences and Research Centre,

Hyderabad, Telangana State, India

ORCID ID: 0000-0002-5779-2542

Email:ayyagarisudha@yahoo.com

Received : June $9^{\text {th }} 2021 ;$ Accepted : August $17^{\text {th }} 2021$

Citation: Ayyagari S, Potnuru A, Saleem SA, Marapaka P. Analysis of frozen section compared to permanent section: A 2 years study in a single tertiary care hospital. J Pathol Nep 2021;12(2):18541858. DOI: $10.3126 /$ jpn.v11i2.37681

Copyright: This is an open-access article distributed under the terms of the Creative Commons Attribution 4.0 International License, which permits unrestricted use, distribution, and reproduction in any medium, provided the original author and source are credited.

\section{INTRODUCTION}

The intraoperative frozen section (FS) method is a means of intraoperative surgical pathology consultation for further management of the case by the surgeon at the time of operation. It was first used by William H Welch from John Hopkin Hospital in 1891 and developed as a diagnostic tool by Cullen Wilson Mc Carty et al. ${ }^{1}$

This practice is now evolved and is used widely in surgical pathology for multiple uses including differentiating benign and malignant neoplasms, identification of tissue and unknown pathological processes, evaluation of margin, identification of lymph node metastasis, confirmation of 
the presence of representative samples for paraffin section diagnosis and to determine the nature of the lesion. ${ }^{2}$ Frozen sectioning is achieved using Cryostat equipment. The indications and limitations of frozen section diagnosis vary in different organs. Diagnostic discrepancies between frozen and permanent sections are commonly observed in tissues from the skin, breast, uterine cervix, and thyroid. ${ }^{2}$ The main purpose is to provide a rapid diagnosis to guide intra and perioperative patient management. ${ }^{3}$

Frozen section diagnosis is conveyed to the operating surgeon within the stipulated time to enable him to make the appropriate decision. The final report includes findings on the frozen section and permanent section and any further tissues sent later. A periodic review of the correlation between frozen section diagnosis and the final diagnosis is useful to identify the potential causes of errors and enables the pathologist to implement the preventive measures. ${ }^{3}$

In this study, we reviewed and compared the diagnosis on frozen sections and permanent sections of various tissues and organs during the 2 years period to assess the diagnostic accuracy and analyse any discrepancy in results.

\section{MATERIALS AND METHODS}

The present study is a 2 years retrospective study on the cases sent for a frozen section in the department of pathology, Kamineni Academy of Medical Sciences and Research Centre from 1st January 2018 to $31^{\text {st }}$ December 2019. Ethical clearance was taken from the institutional board. In this study period, a total of 66 tissues were received for frozen section and intraoperative consultation for various malignant and non-malignant conditions, and records were accessed from a computerised database.

Fresh tissue was sent to our department in a clean plastic container containing normal saline or saline-soaked gauze without any fixative. A duly filled requisition form accompanies the specimen from the operation theatre.

After gross examination and appropriate measurements, the specimens were dissected and bits were given from representative areas. Frozen sectioning was done on Leica CM1520 Cryostat at a temperature range of $-20^{\circ} \mathrm{C}$ to $-22^{\circ} \mathrm{C}$, sections were cut at 4 to 5 microns thickness, immediately stained with rapid $\mathrm{H}$ \& $\mathrm{E}$ (Hematoxylin and Eosin). The stained tissue section was interpreted by at least 2 pathologists and the diagnosis was informed telephonically. The average turnaround time (TAT) was 20 minutes which is well within the TAT specified in the quality assurance criteria of our laboratory. TAT is the time interval between the reception of frozen section specimens in the pathology department to the reporting of diagnosis on a tissue to the operating surgeon. A provisional printed report was sent to the operation theatre for documentation. The remaining tissue of the case received, was fixed in $10 \%$ buffered formalin, grossed and permanent sections prepared from paraffin blocks. After H \& E stain, they were reported and compared with frozen section tissue slides.

The diagnosis was considered as concordant if there was agreement and discordant if there was disagreement with

Table 1: Distribution of cases based on Indication for Frozen section

\begin{tabular}{|lcc|}
\hline Indication for frozen section & Percentage & $\begin{array}{c}\text { Number of } \\
\text { cases }\end{array}$ \\
\hline Definitive diagnosis & 39.40 & 26 \\
\hline Status of Lymph node & 30.30 & 20 \\
\hline To rule out malignancy & 18.18 & 12 \\
\hline $\begin{array}{l}\text { Status of margin in a known case } \\
\text { of malignancy }\end{array}$ & 9.10 & 6 \\
\hline $\begin{array}{l}\text { Presence of ganglion cells in } \\
\text { Hirschsprung's disease }\end{array}$ & 1.51 & 1 \\
\hline $\begin{array}{l}\text { To rule out acute inflammation } \\
\text { in non-union fractures }\end{array}$ & 1.51 & 1 \\
\hline Total & 100 & 66 \\
\hline
\end{tabular}

Table 2: Distribution of Non-neoplastic and Neoplastic lesions on Frozen section

\begin{tabular}{|c|c|c|c|c|}
\hline \multirow[b]{2}{*}{ Site } & \multicolumn{4}{|c|}{ Number of cases } \\
\hline & $\begin{array}{c}\text { Non } \\
\text { Neoplastic }\end{array}$ & Benign & Malignant & Total \\
\hline Lymph node & 10 & 0 & 9 & 19 \\
\hline Breast & 0 & 3 & 5 & 8 \\
\hline Thyroid & 3 & 1 & 2 & 6 \\
\hline Ovary & 1 & 2 & 1 & 4 \\
\hline Endometrium & 0 & 2 & 2 & 4 \\
\hline Kidney & 0 & 0 & 2 & 2 \\
\hline Appendix & 0 & 1 & 1 & 2 \\
\hline Tongue & 1 & 0 & 1 & 2 \\
\hline Liver & 2 & 0 & 0 & 2 \\
\hline Pancreas & 1 & 0 & 0 & 1 \\
\hline Parathyroid & 0 & 1 & 0 & 1 \\
\hline Omentum & 0 & 0 & 1 & 1 \\
\hline Penis & 0 & 0 & 1 & 1 \\
\hline Intestine & 1 & 0 & 0 & 1 \\
\hline Soft tissue & 0 & 1 & 0 & 1 \\
\hline Pelvic mass & 1 & 0 & 0 & 1 \\
\hline $\begin{array}{l}\text { Parametrial } \\
\text { tissue }\end{array}$ & 1 & 0 & 0 & 1 \\
\hline $\begin{array}{l}\text { Peritoneal } \\
\text { deposits }\end{array}$ & 0 & 0 & 1 & 1 \\
\hline $\begin{array}{l}\text { Submandibular } \\
\text { swelling }\end{array}$ & 0 & 0 & 1 & 1 \\
\hline $\begin{array}{l}\text { Paratesticular } \\
\text { mass }\end{array}$ & 1 & 0 & 0 & 1 \\
\hline Others & 1 & 2 & 3 & 6 \\
\hline Total & 23 & 13 & 30 & 66 \\
\hline
\end{tabular}


Table 3: Organ wise accuracy of frozen section

\begin{tabular}{lcccc} 
Anatomical site & $\begin{array}{c}\text { No. of } \\
\text { cases }\end{array}$ & $\begin{array}{c}\text { Concordant } \\
\text { cases }\end{array}$ & $\begin{array}{c}\text { Discordant } \\
\text { cases }\end{array}$ & Accuracy(\%) \\
\hline Lymph node & 19 & 19 & 0 & 100 \\
\hline Breast & 8 & 8 & 0 & 100 \\
\hline Thyroid & 6 & 5 & 1 & 83.33 \\
\hline Ovary & 4 & 4 & 0 & 100 \\
\hline Endometrium & 4 & 4 & 0 & 100 \\
\hline Kidney & 2 & 2 & 0 & 100 \\
\hline Appendix & 2 & 2 & 0 & 100 \\
\hline Tongue & 2 & 2 & 0 & 100 \\
\hline Liver & 2 & 2 & 0 & 100 \\
\hline Pancreas & 1 & 1 & 0 & 100 \\
\hline Parathyroid & 1 & 1 & 0 & 100 \\
\hline Omentum & 1 & 1 & 0 & 100 \\
\hline Penis & 1 & 1 & 0 & 100 \\
\hline Intestine & 1 & 1 & 0 & 100 \\
\hline Soft tissue & 1 & 1 & 0 & 100 \\
\hline Pelvic mass & 1 & 1 & 0 & 100 \\
\hline $\begin{array}{l}\text { Parametrial } \\
\text { tissue }\end{array}$ & 1 & 1 & 0 & 100 \\
\hline $\begin{array}{l}\text { Peritoneal } \\
\text { deposits }\end{array}$ & 1 & 1 & 0 & 100 \\
\hline $\begin{array}{l}\text { Submandibular } \\
\text { swelling }\end{array}$ & 1 & 1 & 0 & 100 \\
\hline $\begin{array}{l}\text { Paratesticular } \\
\text { mass }\end{array}$ & 1 & 1 & 0 & 100 \\
\hline Others & 6 & 6 & 0 & 100 \\
\hline Total & 66 & 65 & 1 & 98.48 \\
\hline & & & & \\
\hline
\end{tabular}

permanent section diagnosis. In discordant cases, slides of both frozen and permanent sections were reviewed along with any further history and investigations by 2 pathologists, the causes were analyzed, documented and the surgeon is informed of the final diagnosis. Deferred cases were defined as indeterminate diagnoses at the time of frozen section and were not found in our study. Hence deferred rate is not included in accuracy as accurate. Special stains and IHC studies were performed as needed. The diagnostic accuracy, sensitivity, and specificity were calculated.

\section{RESULTS}

A total of 66 cases, with an age range of 16 days baby to $83 \mathrm{yrs}$ were studied during the 2 years retrospective study for frozen section and permanent section analysis. The maximum number of cases were in the age range of 51 to 60 years $(24.24 \%)$, followed by 41 to 50 years $(22.72 \%)$ and 31 to 40 years $(19.6 \%)$. Female preponderance was noted in our study. Females constituted $80.3 \%$ and males were $19.6 \%$ of the total cases.

The most common indication was definitive diagnosis (39.39\%), followed by the status of the lymph node in a
Table 4: Comparison of Frozen \& Final diagnosis in discordant case

\begin{tabular}{|c|c|c|c|}
\hline Site & Frozen & Final HP & Reason for discrepancy \\
\hline Thyroid & $\begin{array}{l}\text { Nodular } \\
\text { lymphocytic } \\
\text { thyroiditis }\end{array}$ & $\begin{array}{l}\text { Papillary } \\
\text { carcinoma } \\
\text { with } \\
\text { microscopic } \\
\text { extrathyroidal } \\
\text { invasion in a } \\
\text { background } \\
\text { of nodular } \\
\text { thyroiditis }\end{array}$ & $\begin{array}{l}\text { Carcinoma was missed } \\
\text { in the presence of } \\
\text { predominant thyroiditis } \\
\text { which was seen } \\
\text { diffusely infiltrating } \\
\text { the stroma masking the } \\
\text { cellular details. Frozen } \\
\text { artifacts also made the } \\
\text { identification of nuclear } \\
\text { details difficult to } \\
\text { interpret. }\end{array}$ \\
\hline
\end{tabular}

previously diagnosed case of malignancy $(30.30 \%)$ and other indications were to rule out malignancy $(18.18 \%)$, the status of margins in a known case of malignancy $(9.09 \%)$, presence of ganglion cells in Hirschsprung's disease (1.51\%) and to rule out acute inflammation in non-union fractures (1.51\%) (Table 1). Organ wise correlation of frozen and permanent section diagnosis revealed an accuracy of 98.48 $\%$ (Table 2 and 3 ).

In our study, there were no false-positive or inconsistent cases. The single discordant case was in the category of false-negative and the rest were divided between true positive and true negative cases. Sensitivity was calculated by TP/TP+FN. Specificity was calculated by TN/TN+FP. Concordance was noted in $98.48 \%$ of cases. Discordance was noted in $1.51 \%$ of cases. In the single discordant case, the predominant finding was inflammation in the thyroid nodule which masked the underlying papillary thyroid carcinoma, hence the case was reported as lymphocytic thyroiditis. (Table 4)

\section{DISCUSSION}

The frozen section is a valuable rapid diagnostic tool to assist the surgeon in intraoperative management of surgical procedures by avoiding second surgery and it is of valuable help to the surgeon when there is good communication with pathologists in understanding the surgical implications of the case. ${ }^{9}$ It is costly and requires skill in technique as well as interpretation. Hence this facility is mostly located in major hospitals. Good rapport between surgeon and pathologist is essential to understand the limitations and provide the maximum benefit while conveying the diagnosis.

Even though frozen section provides rapid diagnosis, it should not be used to replace paraffin-embedded tissue technique because of the inherent pitfalls of a limited specimen, freezing artifacts, sampling, section cutting, staining quality, and interpretation. ${ }^{1}$ Close cooperation between the surgeon and the pathologist is needed for a meaningful frozen section report. These limitations in the frozen section need to be taken into consideration while requesting this procedure, to avoid grave mistakes in the 


\begin{tabular}{|c|c|c|c|c|c|c|}
\hline Name of Study & Country & Study period & No. of cases & Accuracy & Sensitivity & Specificity \\
\hline Junn-Liang et $a^{10}$ & China & 1 year & 1084 & $97.7 \%$ & $96.16 \%$ & $99.43 \%$ \\
\hline Farah-Klibi et al ${ }^{11}$ & France & 3 years & 1207 & $97.5 \%$ & 84.6 & 99.8 \\
\hline Shrestha $S$ et al ${ }^{12}$ & India & 5 years & 404 & $94.6 \%$ & 94.56 & 94.55 \\
\hline Fariba Abbasi et al ${ }^{13}$ & Iran & 7 years & 200 & $96.5 \%$ & $93.1 \%$ & $97.7 \%$ \\
\hline Peter $\mathrm{J}$ H et al ${ }^{14}$ & North America & 1 year & 1952 & $96.5 \%$ & - & - \\
\hline Chandramouleeswari $\mathrm{K}$ et $\mathrm{al}^{6}$ & India & 1 year & 51 & $92 \%$ & - & - \\
\hline Present study & India & 2 years & 66 & $98.48 \%$ & $96.87 \%$ & $100 \%$ \\
\hline
\end{tabular}

surgical management of the patient. ${ }^{1}$

The frozen section should be followed by corresponding permanent paraffin sections to give a final opinion. Permanent sections have the advantage of more sampling, identification of surrounding structures, and also to perform any special stains / IHC if required.

In our study, comprising 66 cases in 2 years, the diagnosis on frozen section correlated well with the permanent sections in 65 cases. Analysis of the present study revealed an overall accuracy rate of $100 \%$ in benign lesions and $96.66 \%$ in malignancy. Freezing artifacts were noted in some sections, hence further sections were studied to mitigate the problem. The false-positive rate $(0 \%)$ and false-negative rate $(1.51 \%)$ were well within the range reported in the literature.

Our results were comparable to similar studies for the accuracy, deferral, concordant and discordant rates in the frozen section and permanent section diagnosis. (Table 5)

A similar study by Parikshit $\mathrm{P}$ et al revealed an overall accuracy rate of $96.96 \%$ and a discordant rate of $3.04 \%$. The overall sensitivity and specificity were $97.22 \%$ and $96.30 \%$ respectively. ${ }^{3}$ A similar study by Zubain A et al from a referral centre in Karachi revealed a concordant diagnostic frequency of $97.08 \%$ and discordant frequency of $2.92 \%{ }^{5}$ They noted that the sensitivity of frozen section as a diagnostic test was $98.52 \%$ and positive predictive value was also $98.52 \%$. The average TAT in their centre was 23 minutes. $^{5}$

Chandramouleswari $\mathrm{K}$ et al reported an overall (92\%) concordance percentage over one year. Discordance percentage is $2 \%$ and deferral diagnosis is $6 \%$ which was similar to our study. They noted that discrepancies were mainly due to inherent limitations of frozen sections in organs like the thyroid. ${ }^{6}$ Mourouguessine Vimal et al achieved a concordance rate of $97.85 \%$ and a discordant rate of $2.15 \%$ in their study of 140 frozen section biopsies in a 1year period. ${ }^{7}$

In a study evaluating the accuracy of frozen sections in different anatomical sites, Rafael PS et al observed the highest accuracy (100\%) in tumours of lung, skin, CNS, vulva, vagina, and uterine cervix, whereas the lowest accuracy $(77.7 \%)$ was observed for retroperitoneal tumours. ${ }^{8}$ In a comparative study of frozen section versus paraffin section in the diagnosis of breast lesions, Varnika $\mathrm{K}$ et al found concordance in $94.8 \%$ of cases, the diagnostic accuracy of frozen section in malignant lesions was $100 \%$ and $95.9 \%$ for benign cases.

In an audit of intraoperative frozen section consultation, Satish $\mathrm{S}$ et $\mathrm{al}^{9}$ found that sampling errors of nondiagnostic areas intraoperatively was the reason for the sampling errors $(1.51 \%)$ and interpretation errors were $3.79 \%$, which were attributed to sectioning artifacts, lack / poor quality of morphological details, and presence of the diagnostic area only in the deeper sections. They also noted that technical errors such as sectioning, staining, and labeling may also occur.

In malignant cases, subtyping was not done in most tissues and left for subsequent detailed study in paraffin sections. Since there is a need for an immediate diagnosis and the associated morbidity due to waiting for the frozen section diagnosis, many studies tried to assess, analyse and compare the usefulness of the technique and diagnosis by frozen section and permanent sections.

\section{CONCLUSIONS}

The frozen section was found to be a very useful and accurate procedure for rapid intraoperative consultation for suspicious malignancies, assessing surgical resected margins, primary diagnosis, and staging of tumours. Complete patient history, clinical, imaging findings, and good rapport with operating surgeon play a vital role in accurate diagnosis along with methodical gross examination, accurate sampling, and avoiding technical errors in sectioning and staining. This study also indicates the importance of continuous monitoring and assessment of diagnosis to improve the quality of service provided as well as the thorough knowledge required on frozen section interpretation of different tissues by the pathologist. 


\section{Conflict of interest: None}

\section{REFERENCES}

1. Ashwin T, Vaidik.S, Anil J. Analysis of frozen section in correlation with surgical pathology diagnosis. Int J Res Med Sci 2019;7:2312-27. $\underline{\text { Crossref }}$

2. Pragati.P, Sarita DD. The diagnostic accuracy of frozen section compared to routine histological technique - A comparative study. International J Science Health care Res 2018; 3:88-92. Website

3. Parikshit P, Samarth S. Accuracy of frozen section analysis in correlation with surgical pathology diagnosis. International J Res med sci 2015;3:399-404. Crossref

4. Hassein H, Mohsenifar Z, Alavi SN. The diagnostic accuracy of frozen section compared to permanent section: A single centre study in Iran. Iranian J Pathol 2015;10:295-9. Website

5. Zubair, Muhammed Akbar B, Romana, Yasmin B. Correlation of intraoperative frozen section correlation with the final diagnosis at a referral center in Karachi. Indian J Pathol Micro 2008; 51:469-73. Crossref

6. Chandramouleswari K, Arunalatha P, Jagadeesh C.B, Rajendra A. Frozen and paraffin sections - comparative study highlighting the concordance and discordance rates in a teritiary care centre. IOSR Dental and Med Sci 2013;12:26-30. Crossref

7. Mourouguessive V. A study on accuracy of frozen section diagnosis and turn around time. Int J Health Sci Res 2015;5:138-42. Crossref

8. Rafael PS, Nivaldo SM, Yves RSS, Artur CB, Daniel MT Evaluation of the accuracy of frozen section in different anatomical sites. J Bras. Pathol. Med.Lab 2018; 54:319-24. Crossref

9. Satish SA, Rajalakshmi V, Sundaram k. Intraoperative frozen section consultation - an audit in a teritiary care hospital. Ind J Pathol. Oncol 2018;5:421-8. Crossref

10. Chang JL, T'seng HH, Sheu LF, Lee WH. Diagnostic accuracy of Frozen sections in Surgical Pathology - A retrospective analysis of 1084 frozen sections. Journal of Medical Sciences 1992;13:133-42. Crossref

11. Farah-Klibi F, Neji O, Ferjaoui M, Sfar R et. al. Accuracy of frozen section diagnosis: An analysis of 1695 consecutive cases. Tunis Med. 2008; 86: 693-7. Website
12. Shrestha S, Lee MC, Dhakal H, Pun CB, Pradhan M. Comparative study of Frozen section diagnoses with histopathology. Postgraduate medical journal of NAMS. 2009; 9:1-5. Website

13. Abbasi F, Yekta Z, Aryan A. Accuracy of frozen sections. Iranian Journal of Pathology 2012;7:3-8. $\underline{\text { Website }}$

14. Howanitz PJ, Hoffman GG, Zarbo RJ. The accuracy of frozen section diagnoses in 34 hospitals. Arch Pathol Lab Med 1990;114:355-9. Website 